\title{
Association of HNF4 $\alpha$ gene polymorphisms with susceptibility to type 2 diabetes
}

\author{
RUN MA ${ }^{1}$, HONGYING YANG ${ }^{1}$, JINGFANG LI $^{2}, \mathrm{XU} \mathrm{YANG}^{1}, \mathrm{XIAOHONG} \mathrm{CHEN}^{1}$, \\ YING HU ${ }^{1}, \mathrm{ZHOU}_{\mathrm{WANG}}{ }^{1}$, $\mathrm{LI} \mathrm{XUE}^{1}$ and WEI ZHOU ${ }^{3}$ \\ ${ }^{1}$ Clinical Laboratory, The Second Affiliated Hospital of Kunming Medical University, Kunming, Yunnan 650101; \\ ${ }^{2}$ Clinical Laboratory, Cancer Hospital of Yunnan Province, Kunming, Yunnan 650118; ${ }^{3}$ Department of Ophthalmology, \\ The Third People's Hospital of Yunnan Province, Kunming, Yunnan 650011, P.R. China
}

Received March 24, 2015; Accepted November 6, 2015

DOI: $10.3892 / \mathrm{mmr} .2016 .4780$

\begin{abstract}
The present study aimed to explore the association between single nucleotide polymorphisms (SNPs) in the hepatocyte nuclear factor- $4 \alpha(\mathrm{HNF}-4 \alpha)$ gene and the incidence of type 2 diabetes in the Chinese Bai population in Dali city, China. The polymerase chain reaction-restriction fragment length polymorphism method was used to analyze four SNPs (rs4810424, rs1884613, rs1884614 and rs2144908) in the HNF-4 $\alpha$ gene in 44 patients with type 2 diabetes and 87 healthy controls in Chinese Bai individuals. The haploid type was subsequently built to assess its association with the incidence of type 2 diabetes in the Bai population in Dali city. No significant differences were observed between the genotype and allele frequencies of the four SNPs in the HNF- $4 \alpha$ gene and type 2 diabetes mellitus $(\mathrm{P}>0.05)$. However, the frequency of haplotype, CCTA, built by rs 4810424 , rs1884613, rs1884614 and rs2144908 was significantly higher in the type 2 diabetes mellitus group compared with the control group $\left(\chi^{2}=8.34, \mathrm{P}=0.004\right)$. The four polymorphisms, rs4810424, rs1884613, rs1884614 and rs2144908, in the HNF- $4 \alpha$ gene were not the susceptible loci for type 2 diabetes in the Bai population of Dali city, however, the haplotype, CCTA, built from the four SNPs may increase the risk of type 2 diabetes in this population.
\end{abstract}

\section{Introduction}

With the rising incidence of type 2 diabetes mellitus worldwide, particularly in developing countries (1), type 2 diabetes mellitus has become one of the biggest mortality-causing diseases in humans. In addition to its increasing incidence rate and the trend

Correspondence to: Dr Wei Zhou, Department of Ophthalmology, The Third People's Hospital of Yunnan Province, 292 Beijing Road, Panlong, Kunming, Yunnan 650011, P.R. China

E-mail: weizhoucn@163.com

Key words: type 2 diabetes, hepatocyte nuclear factor- $4 \alpha$, single nucleotide polymorphisms, Chinese Bai population of decreasing age at the onset, type 2 diabetes mellitus is a major health problem, drawing attention worldwide. Type 2 diabetes mellitus has high familial aggregation, and genetic and environmental factors contribute to its incidence synergistically (2). The genetic factors are important in the pathogenesis process of type 2 diabetes (3). Numerous previous studies have demonstrated that the type, number and nature of the mutations in the alleles involved in the pathogenesis of type 2 diabetes may exhibit significant differences among the different ethnic groups or individuals. It was shown that even the different areas in the same ethnic populations were differently correlation between gene polymorphisms and type 2 diabetes. The present study was performed to explore the pathological mechanisms of type 2 diabetes from the genetic factors in order to prevent and treat type 2 diabetes more effectively.

Hepatocyte nuclear factor (HNF) $-4 \alpha$ is a highly conservative member in the nuclear receptor superfamily, with the characteristics of liposoluble hormone receptors. It is normally expressed in the liver, kidney, intestine and pancreas $(4,5)$, and can directly enter into the nucleus to regulate the transcription of genes involved in the regulation of the development, differentiation and function of the islet $\beta$ and liver cells, and the maintenance of the glucose homeostasis (6). In 1996, HNF- $4 \alpha$ was first identified harboring the non-sense mutations of CAG (glutamine) to TAG (amber mutation), termed the Q268X mutant, at +268 by a family linkage analysis on a multigeneration of diabetes family. HNF- $4 \alpha$ was believed to be a disease-causing gene, termed Maturity-Onset Diabetes of the Young 1 (7). In subsequent studies, HNF-4 $\alpha$ was also revealed to be associated with type 2 diabetes $(8,9)$. Previous data revealed that certain genes causing single gene diabetes may also be associated with the susceptibility of type 2 diabetes. The rare mutations of these genes cause single gene diabetes mellitus, while the common polymorphisms in these genes are associated with type 2 diabetes (10). Previous studies also identified that the location of HNF- $4 \alpha$ genes in the chromosome area 20 q13.12 to 20 q13.13 is also a susceptible locus for type 2 diabetes (11) and has a greater frequency of single nucleotide polymorphisms (SNPs). Therefore, HNF-4 $\alpha$ is a candidate gene for type 2 diabetes. However, whether the incidence of type 2 diabetes is correlated with HNF- $4 \alpha$ gene polymorphisms remains to be elucidated. 
Table I. Specific primers for the four SNP sequences and the size of the products.

\begin{tabular}{|c|c|c|c|c|c|}
\hline SNP & Primer & $\begin{array}{l}\text { Size of } \\
\text { product } \\
\text { (bp) }\end{array}$ & $\begin{array}{l}\mathrm{T}_{\mathrm{m}} \\
\left({ }^{\circ} \mathrm{C}\right)\end{array}$ & $\begin{array}{l}\text { Enzyme } \\
\text { recognition } \\
\text { site }\end{array}$ & $\begin{array}{c}\text { Enzyme } \\
\text { digestion } \\
\text { products }(b p)\end{array}$ \\
\hline rs4810424 & $\begin{array}{l}\text { F: 5'-GGGACTACAGGTGAATGCCA-3' } \\
\text { R: 5'-TCCTGTCTATTTCCCAGTGATTC-3' }\end{array}$ & 212 & 58 & SatI $\left(\mathrm{GC}^{\wedge} \mathrm{NGC}\right)$ & $212 / 127 / 85$ \\
\hline rs 1884613 & $\begin{array}{l}\text { F: 5'-TTGAGGACTCGTGATTCGCT-3' } \\
\text { R: 5'-CAGTACCATGCAGTGGGGAT-3' }\end{array}$ & 113 & 56 & Sau3AI (^GATC) & $153 / 114 / 39$ \\
\hline rs1884614 & $\begin{array}{l}\text { F: 5'-GTGTAACTTACCCAGAGGTGC-3' } \\
\text { R: 5'-CAACTTTGGTTTTCACTTCTCA-3' }\end{array}$ & 117 & 56 & $A l w 44 \mathrm{I}\left(\mathrm{G}^{\wedge} \mathrm{TGCAC}\right)$ & $157 / 117 / 40$ \\
\hline rs2144908 & $\begin{array}{l}\text { F: 5'-GTGGGGAACAAGGATGTAAAG-3' } \\
\text { R: 5'-CCCTGATTCTGTCATTCCCT-3' }\end{array}$ & 111 & 56 & $\mathrm{Hae} \mathrm{III}\left(\mathrm{GG}^{\wedge} \mathrm{CC}\right)$ & $151 / 109 / 42$ \\
\hline
\end{tabular}

$\mathrm{T}_{\mathrm{m}}$, melting temperature; F, forward; R, reverse; SNP, single nucleotide polymorphism.

Table II. Hardy-Weinberg equilibrium results of the four single nucleotide polymorphisms near the promoter of the hepatic nuclear factor- $4 \alpha$ gene in the diabetes group and the control group.

\begin{tabular}{|c|c|c|c|c|c|c|c|c|}
\hline \multirow[b]{2}{*}{ Group } & \multicolumn{2}{|c|}{ rs4810424 } & \multicolumn{2}{|c|}{ rs 1884613} & \multicolumn{2}{|c|}{ rs1884614 } & \multicolumn{2}{|c|}{ rs2144908 } \\
\hline & $\chi^{2}$ & $\mathrm{P}$ & $\chi^{2}$ & $\mathrm{P}$ & $\chi^{2}$ & $\mathrm{P}$ & $\chi^{2}$ & $\mathrm{P}$ \\
\hline T2DM & 0.44 & 0.51 & 0.051 & 0.82 & 1.01 & 0.32 & 1.01 & 0.32 \\
\hline $\mathrm{NC}$ & 1.97 & 0.16 & 1.97 & 0.16 & 1.97 & 0.16 & 1.97 & 0.16 \\
\hline
\end{tabular}

T2DM, type 2 diabetes mellitus; NC, normal control.

The correlation between the gene polymorphisms in HNF- $4 \alpha$ and type 2 diabetes has been reported in the populations in North America, Europe and East Asia. A total of four single nucleotide polymorphisms, rs4810424, rs1884613, rs1884614 and rs2144908, near the promoter of the HNF-4 $\alpha$ gene in those populations exhibited different correlations with type 2 diabetes (12-16). However, little research on the minorities in China exists. Yunnan province possesses $>1$ million Bai individuals, who predominantly live in the Dali Bai autonomous prefecture. The Bai nationality is the third biggest minority in Yunnan province, harboring a number of patients with type 2 diabetes. Due to its geographical environment, social mores and the characteristics of population migration, less intermarriage occurs between different nationalities, leading to a relatively isolated genetic population. Therefore, the present study was performed to assess the correlation of the four SNPs, rs4810424, rs1884613, rs1884614 and rs2144904, near the promoter of HNF- $4 \alpha$ gene with the patients type 2 diabetes in the Bai nationality. Additionally, haplotype analysis was also performed to investigate if this can increase the risk of type 2 diabetes in Dali Bai individuals.

\section{Materials and methods}

Patients and individuals. All individuals were of Dali Bai nationality. Patients with type 2 diabetes were diagnosed strictly according to the 1999 diagnostic criteria of diabetes from the World Health Organization (WHO) (17). A total of 44 hospitalized patients with type 2 diabetes in The People's Hospital of Jianchuan County in Dali prefecture from 2010 to 2012, including 20 males and 24 females, were enrolled in this study. The patients were aged between 39 and 77 years. A total of 87 healthy Bai individuals, aged between 35 and 70 years, were recruited as the normal control group. The individuals in the normal control group included 40 males and 47 females, without diabetes, hypertension, coronary heart disease, high cholesterol or other associated diseases. Written informed consent was obtained from each individual and this study was performed in accordance with the declaration of Helsinki. The present study approved by the Ethics Committee of the Second Affiliated Hospital of Kunming Medical University (Kunming, China).

Selection of SNPs. A total of four SNPs (rs4810424, rs1884613, rs1884614 and rs2144904) near the promoter of the HNF-4 $\alpha$ gene were previously reported to be highly correlated with type 2 diabetes in North America, Europe and East Asia. In the present study, these SNPs were selected to assess their association with type 2 diabetes in the Dali Bai individuals.

Detection of gene polymorphisms. DNA samples were extracted from the EDTA-anticoagulant peripheral venous blood collected from each individual. The DNA samples were used for polymerase chain reaction (PCR) amplification, according to the 
manufacturer's instructions in the DNA extraction kit [Tiangen Biotech (Beijing) Co., Ltd., Beijing, China] and PCR amplification kit (Sangon Biotech Co., Ltd., Shanghai, China). Specific primers for the HNF-4 $\alpha$ gene, with an enzyme digestion site for the four SNPs, were designed using Premier 5.0 software (Premier Biosoft, Palo Alto, CA, USA) (Table I) and were synthesized by Sangon Biotech Co., Ltd. PCR-restriction fragment length polymorphism (RFLP) was used to analyze the gene polymorphisms. The PCR conditions were as follows: $3 \mathrm{~min}$ at $95^{\circ} \mathrm{C}, 35$ cycles of $30 \mathrm{sec}$ at $94^{\circ} \mathrm{C}$ and $40 \mathrm{sec}$ at $72^{\circ} \mathrm{C}$, followed by $5 \mathrm{~min}$ at $72^{\circ} \mathrm{C}$. Enzyme digestion reactions were performed on the four PCR products at $37^{\circ} \mathrm{C}$ for $10-12 \mathrm{~h}$ using the corresponding restriction enzymes (SatI, Sau3AI, Alw441 and HaeIII; Bio Basic, Inc., Markham, ON, Canada). The enzyme digestion products were separated using $2 \%$ agarose gel electrophoresis and analyzed using the Tanon 3500 Gel Imaging system (Tanon Science \& Technology Co., Ltd., Shanghai, China). The enzyme digestion products were sequenced using the Sanger method (CapitalBio Corporation, Beijing, China) to confirm the enzyme digestion results.

Statistical analysis. Hardy-Weinberg genetic balance of all subjects in the type 2 diabetes group and normal control group were analyzed using SHEsis software (http://analysis. bio-X.cn/SHEsisMain.htm). The differences of the alleles and genotype frequencies between the two groups were compared using Chi-square test, and subsequently the Odds ratio and 95\% Confidence interval were calculated. Haplotype analysis was performed using SHEsis software. $\mathrm{P}<0.05$ was considered to indicate a statistically significant difference.

\section{Results}

Genotypes of $r s 4810424, r s 1884613, r s 1884614$ and rs 2144904 detected by PCR-RFLP. The genotypes of the four SNPs (rs4810424, rs1884613, rs1884614 and rs2144904) were analyzed using PCR-RFLP. In rs4810424, the GC genotype possessed three bands (212/127/85 bp), the GG genotype only had one band (212 bp) and the CC genotype had two bands (127 and 85 bp; Fig. 1). In rs1884613, three bands in the genotype GC (153/114/39 bp), two bands in the genotype GG (114 and 39 bp) and one band in genotype CC (153 bp; Fig. 2) were observed. As shown in Fig. 3, in rs1884614, three bands represented the CT genotype (40/117/157 bp), two bands represented the CC genotype (40/117 bp), and one band represented the TT genotype (157 bp). In rs2144904, three genotypes, AA (one band; $151 \mathrm{bp}$ ), GG (two bands; 42/109 bp) and AG (three bands; 42/109/151 bp), were observed (Fig. 4). The sequencing results also confirmed the genotyping results of enzyme digestion (Fig. 5).

Hardy-Weinberg equilibrium (HWE) balance of the four SNPS in Dali Bai individuals. The four SNPs, rs4810424, rs1884613, rs1884614 and rs2144904, near the promoter of the HNF-4 $\alpha$ gene in the diabetes group and the control group met the HWE law ( $\mathrm{P}>0.05)$, meaning that all of the four SNPs were in genetic equilibrium with a population representative (Table II).

Correlation of the HNF-4a gene with type 2 diabetes mellitus. The frequencies of the alleles and genotypes of the four SNPs

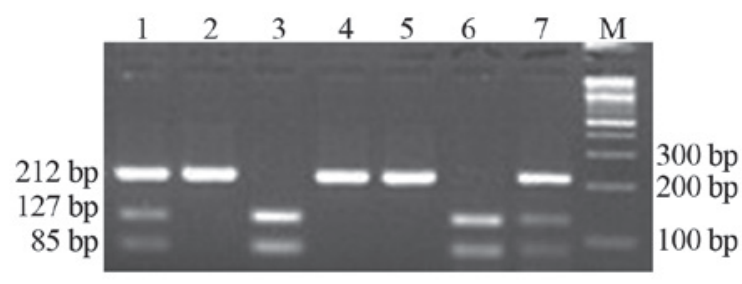

Figure 1. Genotypes of rs4810424 in hepatic nuclear factor- $4 \alpha$ gene, as determined by polymerase chain reaction-restriction fragment length polymorphism analysis. M, marker; lanes 1 and 7, genotype GC; lanes 2, 4 and 5, genotype GG; lanes 3 and 6, genotype $\mathrm{CC}$.

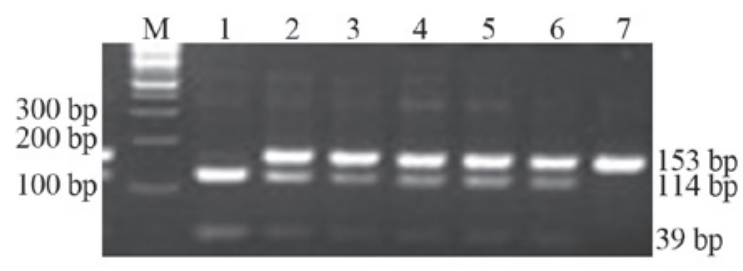

Figure 2. Genotypes of rs1884613 in hepatic nuclear factor-4a gene, as determined by polymerase chain reaction-restriction fragment length polymorphism analysis. M, marker; lane 1, genotype GG; lanes 2 to 6 , genotype GC; lane 7, genotype CC.

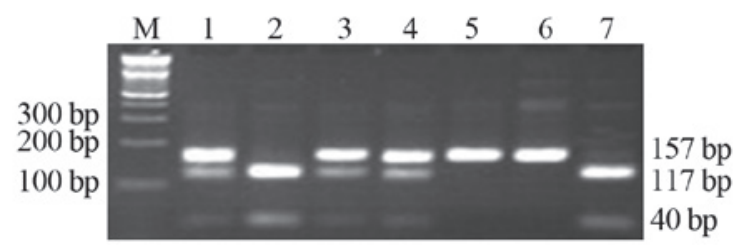

Figure 3. Genotypes of rs1884614 in hepatic nuclear factor- $4 \alpha$ gene, as determined by polymerase chain reaction-restriction fragment length polymorphism analysis. M, marker; lanes 1, 3 and 4, genotype CT; lanes 2 and 7, genotype CC; lanes 5 and 6 , genotype TT.

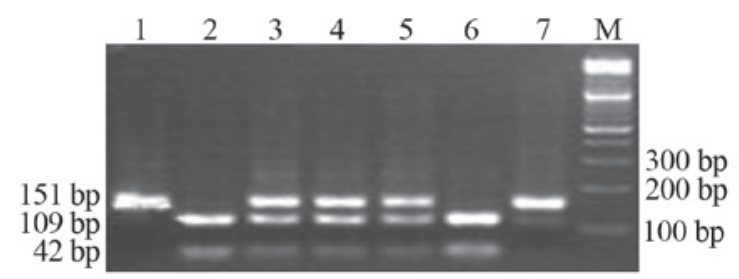

Figure 4. Genotypes of rs2144908 in hepatic nuclear factor-4 $\alpha$ gene, as determined by polymerase chain reaction-restriction fragment length polymorphism analysis. M, marker; lanes 1 and 7, genotype AA; lanes 2 and 6 , genotype GG; lanes 3-5, genotype AG.

near the promoter of the HNF- $4 \alpha$ gene exhibited no statistically significant differences between the diabetes group and the control group in Dali Bai individuals. This suggested that no association existed between rs4810424, rs1884613, rs1884614 and rs2144908, and type 2 diabetes mellitus in Dali Bai individuals ( $\mathrm{P}>0.05$; Table III).

Haplotype analysis of the HNF-4a gene. The ID'Ivalues between each two SNPs were calculated using SHEsis 
Table III. Distribution of the alleles and genotypes of the four single nucleotide polymorphisms near the promoter of hepatic nuclear factor- $4 \alpha$ gene in Dali Bai individuals.

\begin{tabular}{|c|c|c|c|c|c|c|c|c|c|c|}
\hline \multirow{4}{*}{$\begin{array}{l}\text { SNP } \\
\text { rs4810424 }\end{array}$} & \multirow{4}{*}{$\begin{array}{l}\text { Group } \\
\text { T2DM } \\
\text { NC }\end{array}$} & \multicolumn{2}{|c|}{ Alleles [n (\%)] } & \multirow{4}{*}{$\frac{\mathrm{OR}}{1.33(0.79-2.24)}$} & \multirow{4}{*}{$\begin{array}{c}P \\
0.28\end{array}$} & \multicolumn{3}{|c|}{ Genotype [n (\%)] } & \multirow{4}{*}{$\frac{\chi^{2}}{2.92}$} & \multirow{4}{*}{$\begin{array}{r}\mathrm{P} \\
0.23\end{array}$} \\
\hline & & $\mathrm{C}$ & G & & & $\mathrm{CC}$ & $\mathrm{CG}$ & GG & & \\
\hline & & $40(45.5)$ & $48(54.5)$ & & & $8(18.2)$ & $24(54.5)$ & $12(27.3)$ & & \\
\hline & & $67(38.5)$ & $107(61.5)$ & & & $16(18.4)$ & 35 (40.2) & $36(41.4)$ & & \\
\hline \multirow{3}{*}{ rs 1884613} & & $\mathrm{C}$ & $\mathrm{G}$ & \multirow{3}{*}{$0.90(0.54-1.53)$} & \multirow{3}{*}{0.71} & $\mathrm{CC}$ & $\mathrm{CG}$ & GG & \multirow{3}{*}{1.14} & \multirow{3}{*}{0.56} \\
\hline & $\mathrm{T} 2 \mathrm{DM}$ & $52(59.1)$ & $36(40.9)$ & & & $15(34.1)$ & $22(50.0)$ & 7 (15.9) & & \\
\hline & $\mathrm{NC}$ & $107(61.5)$ & 67 (38.5) & & & $36(41.4)$ & $35(40.2)$ & $16(18.4)$ & & \\
\hline \multirow{3}{*}{ rs1884614 } & & $\mathrm{C}$ & $\mathrm{T}$ & \multirow{3}{*}{$0.79(0.47-1.32)$} & \multirow{3}{*}{0.37} & $\mathrm{CC}$ & $\mathrm{CT}$ & $\mathrm{TT}$ & \multirow{3}{*}{3.45} & \multirow{3}{*}{0.18} \\
\hline & $\mathrm{T} 2 \mathrm{DM}$ & $49(55.7)$ & $39(44.3)$ & & & $12(27.3)$ & $25(56.8)$ & 7 (15.9) & & \\
\hline & $\mathrm{NC}$ & $107(61.5)$ & 67 (38.5) & & & $36(41.4)$ & $35(40.2)$ & $16(18.4)$ & & \\
\hline \multirow{3}{*}{ rs2144908 } & & $\mathrm{A}$ & $\mathrm{G}$ & \multirow{3}{*}{$1.27(0.76-2.14)$} & \multirow{3}{*}{0.37} & AA & $\mathrm{AG}$ & GG & \multirow{3}{*}{3.45} & \multirow{3}{*}{0.18} \\
\hline & $\mathrm{T} 2 \mathrm{DM}$ & $39(44.3)$ & $49(55.7)$ & & & 7 (15.9) & $25(56.8)$ & $12(27.3)$ & & \\
\hline & $\mathrm{NC}$ & $67(38.5)$ & $107(61.5)$ & & & $16(18.4)$ & $35(40.2)$ & $36(41.4)$ & & \\
\hline
\end{tabular}

T2DM, type 2 diabetes mellitus; NC, normal control.

Table IV. Correlation of the frequencies of haplotypes in the hepatic nuclear factor- $4 \alpha$ gene with type 2 diabetes in Dali Bai individuals.

\begin{tabular}{|c|c|c|c|c|c|}
\hline SNPs & Haplotype & $\mathrm{T} 2 \mathrm{DM}[\mathrm{n}(\%)]$ & $\mathrm{NC}[\mathrm{n}(\%)]$ & $\chi^{2}$ & $\mathrm{P}$ \\
\hline rs $4810424+$ rs $1884613+$ rs $1884614+$ rs 2144908 & CGTA & $35.0(39.7)$ & $67(38.5)$ & 0.11 & 0.74 \\
\hline rs $4810424+$ rs $1884613+$ rs $1884614+$ rs 2144908 & GCCG & $47.0(53.3)$ & $107(61.5)$ & 1.13 & 0.29 \\
\hline rs $4810424+$ rs $1884613+$ rs $1884614+$ rs 2144908 & CCTA & $4.0(4.6)$ & $0(0.00)$ & 8.34 & 0.004 \\
\hline rs $4810424+$ rs $1884613+$ rs $1884614+$ rs2144908 & GGCG & $1.0(1.2)$ & $0(0.00)$ & NA & NA \\
\hline rs $4810424+$ rs $1884613+$ rs $1884614+$ rs2144908 & CCCG & $1.0(1.1)$ & $0(0.00)$ & NA & NA \\
\hline
\end{tabular}

SNP, single nucleotide polymorphism; T2DM, type 2 diabetes mellitus; NC, normal control.

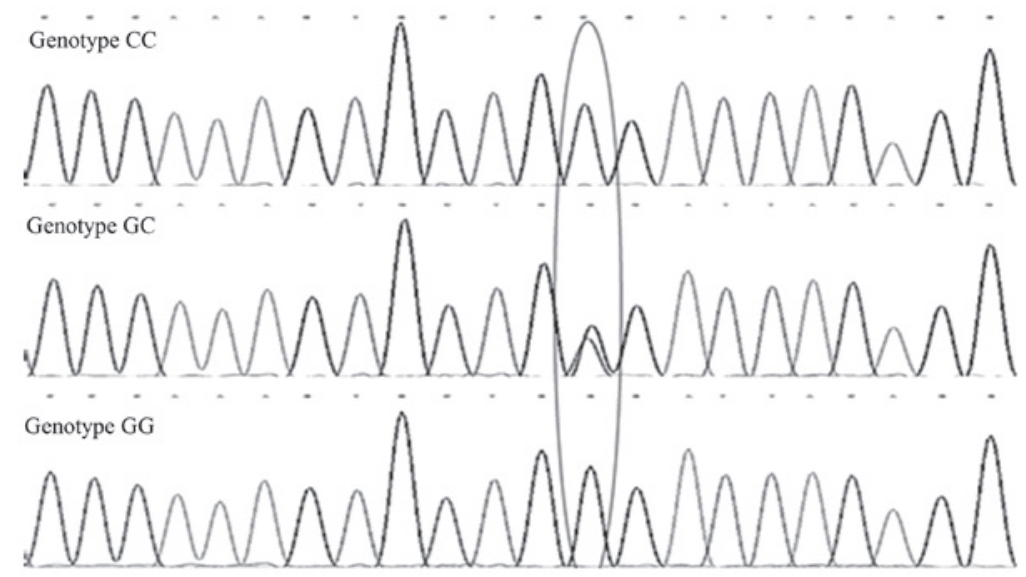

Figure 5. Sequencing results of rs4810424.

software, to measure the linkage disequilibrium tight degrees between the loci (Fig. 6). From the values, it was observed that a marked linkage disequilibrium existed between the four SNPs, which can build haploid types. The four SNPs in the HNF- $4 \alpha$ gene (rs4810424, rs1884613, rs1884614 and rs2144908) built three main haploid types: CGTA, GCCG and CCTA. The frequencies of haplotype CGTA in the type 2 diabetes group and normal control group exhibited a significant difference $\left(\chi^{2}=8.34, \mathrm{P}<0.004\right)$, while the other haplotypes revealed no marked differences between the two groups (Table IV). 


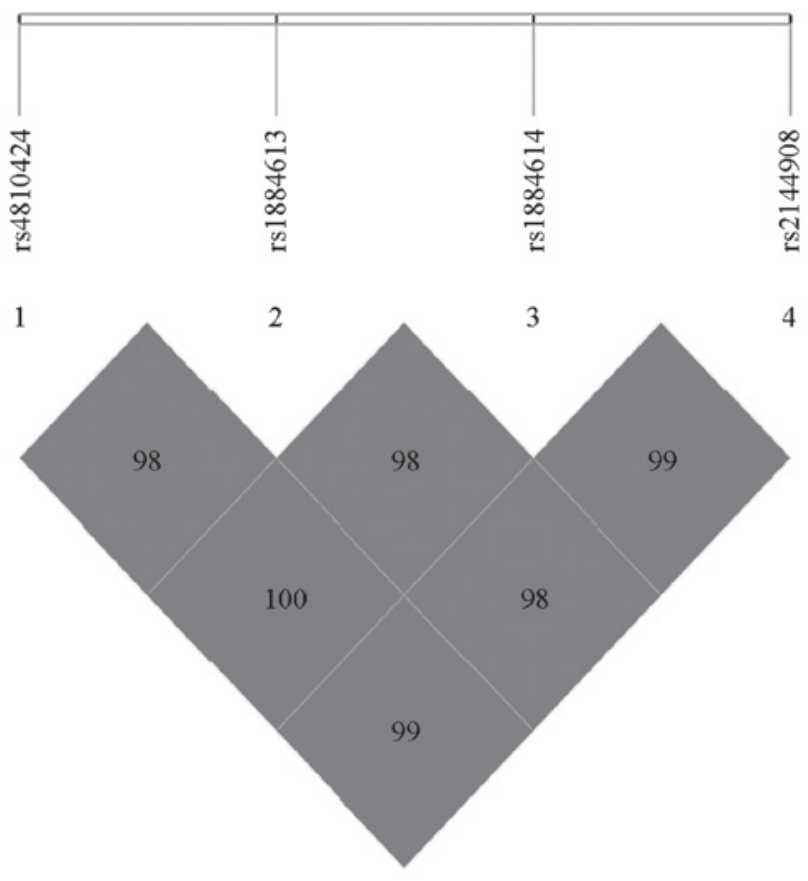

Figure 6. A direct-viewing graph of ID'l test.

\section{Discussion}

It is widely reported that the HNF- $4 \alpha$ gene is correlated with type 2 diabetes. In 1998, Hani et al (18) demonstrated that certain genetic marker loci in the HNF- $4 \alpha$ gene are associated with type 2 diabetes, as determined by a genescan on the French diabetes family constellations. A missense mutation in HNF- $4 \alpha+393$ makes valine transform into isoleucine, which is cosegregated with diabetes and associated with the impaired insulin secretion. It was determined that the mutation can reduce the transcriptional activity of the insulin gene in vitro. Subsequently, a study on German Jewish individuals by Love-Gregory et al (12) also identified that SNPs, including rs4810424, rs1884613, rs1884614 and rs2144908, in the HNF-4 $\alpha$ gene are closely associated with type 2 diabetes to different extents. Barroso et al (19) and Neuman et al (20) also confirmed the correlation of rs1884613 and/or rs2144908 with type 2 diabetes in a population of Ashkenazi Jews. In Finland, using the analysis method of the involved siblings, Silander et al (11) located the susceptibility genes of type 2 diabetes in chromosome 20 q13.12 to 20 q13.13, which is the location of the HNF- $4 \alpha$ gene. One of the most significant associated sites with type 2 diabetes is rs2144908, located near the P2 promoter of HNF-4 $\alpha$ gene. However, in Japan, Hara et al (13) revealed that the allele and genotype frequencies of two SNPs, rs1884614 and rs2144908, near the P2 gene promoter of HNF- $4 \alpha$ gene was not associated with type 2 diabetes in a Japanese population. However, the built haploid type is significantly associated with type 2 diabetes, which is negatively correlated with the distances between the SNP and the P2 promoter region. However, there are differing opinions regarding the association of $\mathrm{HNF} 4 \alpha$ gene polymorphisms with type 2 diabetes. For instance, Tokunaga et al (14) revealed no association between the haploid type established by rs2144908 and rs1884614, and type 2 diabetes in Japanese individuals. Vaxillaire et al (15) revealed no correlation of the two SNPs near the P2 promoter with type 2 diabetes in French individuals. Winckler et al (16) also provided a negative conclusion in an investigation on the populations in Sweden, Canada and Finland. In China, no association was observed between rs2144908, rs1884614 and rs1884613, and type 2 diabetes in Chinese Han individuals (21-23). Due to the different ethnic backgrounds and sample sizes, the association of SNPs in the HNF-4 $\alpha$ gene with type 2 diabetes mellitus were ethnically and regionally different. The different ethnic groups or individuals may cause different gene types, number and nature of the mutations involved in diabetes. Therefore, preliminary investigations on different groups revealed diverse polymorphic loci in the susceptibility genes.

The inconsistent results from the different areas or races also reflect the genetic heterogeneity of type 2 diabetes. In the area 20 q13.12 to 20 q13.13, associated with type 2 diabetes, there may be genetic heterogeneity and differences caused by the environmental factors and/or genetic backgrounds. The over assessment of the high incidence of type 2 diabetes possibly results from the individuals from the family constellation of type 2 diabetes, however was not ruled out until now. In addition, the small sample size may also lead to false negative or false positive results.

In the present study, it was revealed that the allele and genotype frequencies of four SNPs in the HNF-4 $\alpha$ gene (rs4810424, rs1884613, rs1884614 and rs2144908) presented no prominent difference between the type 2 diabetes mellitus group and the healthy control group in the Dali Bai population. However, the haplotype analysis revealed that there was an associated disequilibrium between the four SNPs in the HNF- $4 \alpha$ gene and the frequency of the haploid type, CCTA, increased significantly in the patients with type 2 diabetes mellitus in the Dali Bai population $(\mathrm{P}=0.004)$, suggesting that rs4810424, rs1884613, rs1884614 and rs2144908 in the HNF-4 $\alpha$ gene are not susceptibility loci for type 2 diabetes in the Dali Bai population. However, the existence of the haploid type, CCTA, built by the four SNPs may increase the risk of type 2 diabetes in Dali Bai individuals. Haplotype refers to a collection of specific alleles in a cluster of tightly-linked genes on a chromosome, which are likely to be inherited together. It has been reported that haplotype analysis is often more meaningful compared with a single polymorphic locus analysis (13). According to the results of the present study, the frequency of haplotype CCTA increased significantly in the patients with type 2 diabetes mellitus in the Dali Bai population and it was hypothesized that the synergetic effect of the four SNPs may change the functional regions of HNF- $4 \alpha$ gene and thereby affect the susceptibility of type 2 diabetes in the Dali Bai population. Additionally, due to the difficulty of collecting samples from patients with type 2 diabetes in the Bai population with three generations of pure Bai line, the small sample size may lead to certain differences in the results. A larger sample size would be required in future investigations.

\section{Acknowledgements}

The present study was supported by a grant from the Health Science and Technology Plan of Yunnan Province, China (no. 2011WS0103). 


\section{References}

1. Shaw JE, Sicree RA and Zimmet PZ: Global estimates of the prevalence of diabetes for 2010 and 2030. Diabetes Res Clin Pract 87: 4-14, 2010

2. Tang LL, Liu Q, Bu SZ, Xu LT, Wang QW, Mai YF and Duan SW: The effect of environmental factors and DNA methylation on type 2 diabetes mellitus. Yi Chuan 35: 1143-1152, 2013 (In Chinese).

3. Brunetti A, Chiefari E and Foti D: Recent advances in the molecular genetics of type 2 diabetes mellitus. World J Diabetes 5: 128-140, 2014.

4. Nammo T, Yamagata K, Tanaka T, Kodama T, Sladek FM, Fukui K, Katsube F, Sato Y, Miyagawa J and Shimomura I: Expression of HNF-4alpha (MODY1), HNF-1beta (MODY5), and HNF-1alpha (MODY3) proteins in the developing mouse pancreas. Gene Expr Patterns 8: 96-106, 2008.

5. Babeu JP and Boudreau F: Hepatocyte nuclear factor 4-alpha involvement in liver and intestinal inflammatory networks. World J Gastroenterol 20: 22-30, 2014.

6. Gupta RK, Vatamaniuk MZ, Lee CS, Flaschen RC, Fulmer JT, Matschinsky FM, Duncan SA and Kaestner KH: The MODY1 gene HNF-4alpha regulates selected genes involved in insulin secretion. J Clin Invest 115: 1006-1015, 2005.

7. Yamagata K, Furuta H, Oda N, Kaisaki PJ, Menzel S, Cox NJ, Fajans SS, Signorini S, Stoffel M and Bell GI: Mutations in the hepatocyte nuclear factor- $4 \alpha$ gene in maturity-onset diabetes of the young (MODY1). Nature 384: 458-460, 1996.

8. Johansson S, Raeder H, Eide SA, Midthjell K, Hveem K, Søvik O, Molven A and Njølstad PR: Studies in 3,523 Norwegians and meta-analysis in 11,571 subjects indicate that variants in the hepatocyte nuclear factor 4 alpha (HNF4A) P2 region are associated with type 2 diabetes in Scandinavians. Diabetes 56: 3112-3117, 2007.

9. Cho YS, Chen CH, Hu C, Long J, Ong RT, Sim X, Takeuchi F, Wu Y, Go MJ, Yamauchi T, et al; MuTHER Consortium: Meta-analysis of genome-wide association studies identifies eight new loci for type 2 diabetes in east Asians. Nat Genet 44: 67-72, 2011.

10. Jafar-Mohammadi B1, Groves CJ, Gjesing AP, Herrera BM, Winckler W, Stringham HM, Morris AP, Lauritzen T, Doney AS, Morris AD, et al; DIAGRAM Consortium: A role for coding functional variants in HNF4A in type 2 diabetes susceptibility. Diabetologia 54: 111-119, 2011.

11. Silander K, Mohlke KL, Scott LJ, Peck EC, Hollstein P, Skol AD, Jackson AU, Deloukas P, Hunt S, Stavrides G, et al Genetic variation near the hepatocyte nuclear factor- $4 \alpha$ gene predicts susceptibility to type 2 diabetes. Diabetes 53: 1141-1149, 2004.

12. Love-Gregory LD, Wasson J, Ma J, Jin CH, Glaser B, Suarez BK and Permutt MA: A common polymorphism in the upstream promoter region of the hepatocyte nuclear factor- $4 \alpha$ gene on chromosome $20 \mathrm{q}$ is associated with type 2 diabetes and appears to contribute to the evidence for linkage in an ashkenazi jewish population. Diabetes 53: 1134-1140, 2004.
13. Hara K, Horikoshi M, Kitazato H, Ito C, Noda M, Ohashi J, Froguel P, Tokunaga K, Tobe K, Nagai R, et al: Hepatocyte nuclear factor-4alpha $\mathrm{P} 2$ promoter haplotypes are associated with type 2 diabetes in the Japanese population. Diabetes 55: 1260-1264, 2006.

14. Tokunaga A, Horikawa Y, Fukuda-Akita E, Okita K, Iwahashi H, Shimomura I, Takeda J and Yamagata K: A common $\mathrm{P} 2$ promoter polymorphism of the hepatocyte nuclear factor- $4 \alpha$ gene is associated with insulin secretion in non-obese Japanese with type 2 diabetes. Endocr J 55: 999-1004, 2008.

15. Vaxillaire $M$, Dina $C$, Lobbens $S$, Dechaume A, Vasseur-Delannoy V, Helbecque N, Charpentier G and Froguel P: Effect of common polymorphisms in the HNF4alpha promoter on susceptibility to type 2 diabetes in the French Caucasian population. Diabetologia 48: 440-444, 2005.

16. Winckler W, Graham RR, de Bakker PI, Sun M, Almgren P, Tuomi T, Gaudet D, Hudson TJ, Ardlie KG, Daly MJ, et al: Association testing of variants in the hepatocyte nuclear factor 4alpha gene with risk of type 2 diabetes in 7,883 people. Diabetes 54: 886-892, 2005.

17. World Health Organization: Definition, Diagnosis and Classification of Diabetes Mellitus and its Complications: Report of a WHO Consultation. Part 1: Diagnosis and Classification of Diabetes Mellitus. World Health Organization, Geneva, 1999.

18. Hani EH, Suaud L, Boutin P, Chèvre JC, Durand E, Philippi A, Demenais F, Vionnet N, Furuta H, Velho G, et al: A missense mutation in hepatocyte nuclear factor-4 alpha, resulting in a reduced transactivation activity, in human late-onset non-insulin-dependent diabetes mellitus. J Clin Invest 101: 521-526, 1998

19. Barroso I, Luan J, Wheeler E, Whittaker P, Wasson J, Zeggini E, Weedon MN, Hunt S, Venkatesh R, Frayling TM, et al: Population-specific risk of type 2 diabetes conferred by HNF4A P2 promoter variants. Diabetes 57: 3161-3165, 2008

20. Neuman RJ, Wasson J, Atzmon G, Wainstein J, Yerushalmi Y, Cohen J, Barzilai N, Blech I, Glaser B and Permutt MA: Gene-gene interactions lead to higher risk for development of type 2 diabetes in an Ashkenazi Jewish population. PLoS One 5: e9903, 2010

21. Wang F, Han XY, Ren Q, Zhang XY, Han LC, Luo YY, Zhou XH and Ji LN: Effect of genetic variants in KCNJ11, ABCC8, PPARG and HNF4A loci on the susceptibility of type 2 diabetes in Chinese Han population. Chin Med J (Engl) 122: 2477-2482, 2009.

22. Chen Z, Zhang D, Liu Y, Zhou D, Zhao T, Yang Y, He L and $\mathrm{Xu} H$ : Variants in hepatocyte nuclear factor $4 \alpha$ gene promoter region and type 2 diabetes risk in Chinese. Exp Biol Med (Maywood) 235: 857-861, 2010.

23. Wang C, Chen S, Zhang T, Chen Z, Liu S, Peng X, Ma J, Zhong X, Yan Y, Tang L, et al: Prediabetes is associated with HNF-4 $\alpha$ P2 promoter polymorphism rs1884613: A case-control study in Han Chinese population and an updated meta-analysis. Dis Markers 2014: 231736, 2014. 